\title{
Comments on the Case Study „The Pilkington Sandoglass Case a British - Polish Joint Venture“.
}

\author{
Krzysztof Konecki*
}

The text of the case study is a very good example of the teaching device used for the students of business schools. There is a very good description of timing of transformation, a logical structure and clear exhibits that are very helpful in understanding of the text. It is possible to use it in teaching in the format as it is now. However, basing on my teaching experience in private business schools I have some comments on the text. The easiest task to do after reading the text is an analysis of the structure of organisation before and after the enterprise transformation.

It would be difficult to analyse, for example, the change in people's attitudes and behaviours or even a corporate culture (see the question 1 on the page 18). There are not enough data on the subjects. On the page 10 there are two sentences: "The board of employees was elected by the workers of the company. Their main purpose was to control the director's decision and to reject it in the case it ran against their interests." It may be true, but not a total true. The board of employees (or maybe 'worker's council') was a collective body to express not only the interests of a workers but also it was the organisational channel of communication of the all echelons of organisational structure with a top management. If we stop description of the board of employees, in the 'case study', on the only two sentences we confirm only the extremely technocratic approach that dominates now in the post - communist economies. The teaching of the future managers should be more sensitive to the channels of communication in the enterprises (bottom up or others). I have some general objections against the technocratic approach that dominate the curricula of business schools, at least in Poland. It would be helpful to add some endnotes to the text explaining more the technical terms in the context of organisation of work: sheet glass production technology, plate glass production technology and float glass technology. What are the main differences, advantages, disadvantages etc.?It is not a negative estimation of the 'case study'. I think it is a very good device to teach students, even in the format that was sent to me.

\footnotetext{
* Krzysztof Konecki, Institute of Sociology, University Lodz
} 